\title{
Characterization of an agricultural site historically polluted by the destruction of arsenic-containing chemical weapons
}

\author{
F. Battaglia-Brunet ${ }^{1}$, J. Lions ${ }^{1}$, C. Joulian ${ }^{1}$, N. Devau ${ }^{1}$, M. Charron ${ }^{1}$, D. Hube ${ }^{1}$, J. Hellal ${ }^{1}$, \\ M. Le Guédard ${ }^{2}$, I. Jordan ${ }^{3}$, P. Bhattacharya ${ }^{4}$, K. Loukola-Ruskeeniemi ${ }^{5}$, T. Tarvainen ${ }^{5}$ \& J. Kaija ${ }^{5}$ \\ ${ }^{1}$ BRGM, Orléans, France \\ ${ }^{2}$ LEB Aquitaine Transfert, Villenave d'Ornon, France \\ ${ }^{3}$ GEOS Ingenieurgesellschaft mbH, Halsbrücke, Germany \\ ${ }^{4}$ KTH-Groundwater Arsenic Research Group, Department of Sustainable Development, Environmental Science and \\ Engineering, KTH Royal Institute of Technology, Stockholm, Sweden \\ ${ }^{5}$ Geological Survey of Finland, Espoo, Finland
}

\begin{abstract}
Arsenic in agricultural soils may represent a risk for crop quality and surrounding water resources. In the frame of AgriAs project, "Evaluation and management of Arsenic contamination in agricultural soil and water", a former chemical weapons destruction site converted into agricultural land was characterized. The objective of this study was to identify possible links between arsenic concentration and speciation and bioindicators informing about the bioavailability of the toxic element. Plants lipidic bio-indicator Omega-3 Index showed that toxicity of the soil was not directly correlated with arsenic concentration. Conversely, arsenic level in the soil samples seemed to influence the density of microbes transforming As species.
\end{abstract}

\section{INTRODUCTION}

Arsenic (As) and its compounds are toxic and ubiquitous in the environment. It has been estimated that over 220 million people are exposed to As from drinking water or food (Naujokas et al., 2013). Arsenic in agricultural soils and water, and its subsequent entering into the food chain cause potential risk to human health. Indeed, As can accumulate in crop plants such as corn or barley. High As concentrations may also reduce crop yields. Production, destruction and storage of As-rich chemical weapons have increased As concentrations in the European environment. The present study, performed in the framework of the WaterJPI AgriAs project, is focused on the elucidation of the links between As concentration and speciation in soils and a range of bio-indicators that could be helpful to understand the behavior and bio-availability of arsenic in agricultural soils.

\section{METHODS/EXPERIMENTAL}

\subsection{Site description and sampling}

The sampling site is a former chemical ammunition breaking-down facility of the interwar period converted into agricultural land near Verdun, France. The field is located $25 \mathrm{~km}$ north-east from Verdun. The field was used as a pasture in 2002 and was cultivated from 2002 to 2015. Since 2015, it is a fallow ground because cultivation was forbidden when the pollution was detected. The sampling was performed in May 2017. Many plant species could be observed. The diversity was lower in the most polluted places but plants were observed even in those places. Soils were sampled in a reference zone, far from the polluted area, and along a three-zones transect representing a gradient of As pollution. Soils were sampled in the $0-20 \mathrm{~cm}$ layer. Each sample was taken as a composite of 5 points from $3 \mathrm{~m} \times 3 \mathrm{~m}$ squares.

\subsection{Chemical analyzes}

Arsenic concentration in the soil surfaces was determined on site with X-ray fluorescence (NITON) apparatus. Speciation of arsenic was performed by HPLC-ICP-MS after $\mathrm{H}_{3} \mathrm{PO}_{4}$ extraction. Diphenylarsinc acid was determined by HPLC-DAD and apolar organoarsenicals by $\mathrm{GC} / \mathrm{MS}$.

\subsection{Bio-indicators}

As(III)-oxidizing and As(V)-reducing microbial concentrations were evaluated by Most Probable Number methods (5 tubes), using specific media in microplates. As(III) was visualized in the wells by adding pyrrolidine dithio-carbamate (Thouin et al., 2016). Plants were collected in the four zones described previously. On the reference, low and medium zones, three and five species of plants were collected to measure As bioavailability and the lipidic bioindicator Omega-3 Index. Arsenic bioavailability was analyzed from collected plants by ICP-MS after mineralization by acid 
Table 1. Concentration of arsenic species in the soil samples. ND: not detected

\begin{tabular}{lccll}
\hline Zones & $\begin{array}{l}\mathrm{As}(\mathrm{V}) \\
\mathrm{mg} \mathrm{kg}^{-1}\end{array}$ & $\begin{array}{l}\mathrm{As}(\mathrm{III}) \\
\mathrm{mg} \mathrm{kg}^{-1}\end{array}$ & $\begin{array}{l}\text { Diphelylarsinic } \\
\mathrm{acid} \mathrm{mg} \mathrm{kg}^{-1}\end{array}$ & $\begin{array}{l}\text { Triphenylarsnine } \\
\mathrm{mg} \mathrm{kg}^{-1}\end{array}$ \\
\hline $\begin{array}{l}\text { Reference } \\
\text { Transect }\end{array}$ & 15 & 0.3 & $\mathrm{ND}$ & $\mathrm{ND}$ \\
Low & 20 & 0.2 & $\mathrm{ND}$ & $\mathrm{ND}$ \\
Transect & 192 & 1.4 & $\mathrm{ND}$ & $\mathrm{ND}$ \\
$\begin{array}{l}\text { Medium } \\
\text { Transect }\end{array}$ & 756 & 14.4 & 2.19 & 0.95 \\
High & & & & \\
\hline
\end{tabular}

attack. For the measurement of the lipidic bioindicator, the leaf fatty acid composition was analyzed by GC-FID on the plants collected on the site but also on lettuces grown under controlled conditions on the four collected soils.

\section{RESULTS AND DISCUSSION}

\subsection{Arsenic in soil}

Arsenic concentration varied from $15 \mathrm{mg} \mathrm{kg}^{-1}$ in the reference not polluted area of the site, to $775 \mathrm{mg} \mathrm{kg}^{-1}$ in the highly polluted spot (Table 1).

The main arsenic form was arsenate (As(V)), however As(III) proportion was higher in the polluted spot. Two organic molecules derived from the weapons were detected only in the highly polluted zone: diphenylarsinic acid and thriphenylarsine.

\subsection{Bio-indicators}

The collected plants were Brassica napus, Plantago major, Carduus sp. in the reference zone; Brassica napus, Plantago major, Carduus sp., and Chamaemelum nobilis in the low-pollution zone; Brassica napus, Plantago major, Carduus sp. and Chamaemelum nobilis in the medium-polluted zone; Carduus sp., and Chamaemelum nobilis in the highpollution zone. Unidentified species were also collected in all zones except the highly-polluted one. Arsenic was more phytoavailable on the medium polluted soil than on the reference and the low polluted soils for all the three species collected. On the highly polluted soil, only one species could be analyzed. For this species, the As content was higher in the highly polluted zone. However, regardless of the zones, the As content in plants was very low compared to plants found on other As-polluted sites. In both site plants and lettuces, the lipidic bioindicator was lower on the medium polluted soil. It seems that the medium polluted soil was the most toxic for plants. This result might be interpreted in the light of further soil characterizations. As(III)-oxidizing microbes were more numerous in the highly polluted soils than
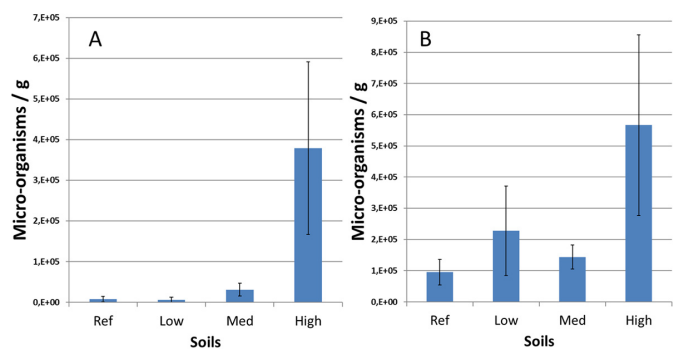

Figure 1. Evaluation by MPN methods of As(III)-oxidizing (A) and As(V)-reducing (B) microorganisms in the soil samples.

in the other samples. The same tendency was observed for $\mathrm{As}(\mathrm{V})$-reducing microbes, but less significantly (Fig. 1).

\section{CONCLUSIONS}

Whereas the studied site was polluted one century ago, and was used for agriculture for years, impact of the pollution level is still observable on the diversity of wild plants. Arsenic level seems to exert influence on the soil composition in As-transforming microbes. These results suggest that arsenic was sufficiently bio-available to exert a selection pressure on the microbial communities. Next experimental steps will include the study of the influence of agricultural practices on the fate of As, through a biogeochemical approach including modelling, and connected with risk assessment.

\section{ACKNOWLEDGEMENTS}

AgriAs is co-funded by EU and the Academy of Finland, L'Agence Nationale de la Recherche, Bundesministerium für Ernährung und Landwirtschaft and Forskningsrådet FORMAS under the ERA-NET Cofund WaterWorks2015 Call. This ERA-NET is an integral part of the 2016 Joint Activities developed by the Water Challenges for a Changing World Joint Programme Initiative (Water JPI).

\section{REFERENCES}

Naujokas, M.F., Anderson, B., Ahsan, H., Vasken Aposhian, H., Graziano, J.H., Thompson, C. \& Suk, W.A. 2013. The broad scope of health effects from chronic arsenic exposure: update on a worldwide public health problem. Environ. Health Persp. 121, 295-302.

Thouin, H., Le Forestier, L., Gautret, P., Hube, D., Laperche, V., Dupraz, S., \& Battaglia-Brunet, F. 2016. Characterization and mobility of arsenic and heavy metals in soils polluted by the destruction of arsenic-containing shells from the Great War. Sci. Total Environ. 550: 658-669. 